\title{
Influences of Interfacial Shear in Turbulent Film Boiling on a Horizontal Tube with External Flowing Liquid
}

\author{
Hai-Ping Hu \\ Department of Marine Engineering, National Taiwan Ocean University, Taiwan \\ Email: hphu@ntou.edu.tw
}

Received 31 October 2015; accepted 23 November 2015; published 26 November 2015

Copyright (C) 2015 by author and Scientific Research Publishing Inc.

This work is licensed under the Creative Commons Attribution International License (CC BY). http://creativecommons.org/licenses/by/4.0/

c) (i) Open Access

\begin{abstract}
The paper presents a theoretical study about turbulent film boiling on a horizontal tube with external flowing liquid. The high velocity flowing liquid is determined by potential flow theory. By using Colburn analogy, the present paper successfully addresses a new model to predict the vaporliquid interfacial shear, applies the interfacial shear into the forced balance equation and then combines the forced balance equation, the energy equation and thermal energy balance equation. At last, both the film thickness and Nusselt number can be obtained. Besides, the present analysis also includes radiation effects, temperature ratio and eddy diffusivity. Finally, a comparison between the results of the present study and those reported in previous theoretical and experimental studies is provided.
\end{abstract}

\section{Keywords}

Eddy Diffusivity, Potential Flow, Colburn Analogy

\section{Introduction}

The research of film boiling on a horizontal tube was conducted by the pioneering investigator, Bromley [1]. After Bromley's research, many related researches had been reported. In 1966, Nishikawa et al. [2] analyzed two-phase boundary-layer treatment of free-convection film boiling. The theoretical study had been made of film boiling from an isothermal vertical plate and a horizontal cylinder without considering radiative effects. Jordan [3] investigated the laminar film boiling and transition boiling, and the separated region had also been discussed. Sakurai et al. [4] presented the pool film boiling on a horizontal cylinder with theoretical solutions. The analytical heat transfer model is based on laminar boundary theory including radiation effects. For the 
forced convection film boiling, Huang et al. [5] investigated the flow film boiling across a horizontal cylinder with uniform heat flux. The numerical results agreed with those experimental data where the wall temperature did not vary a lot around the heater at high heat fluxes, within $\pm 18 \%$.

Laminar film boiling on horizontal tubes has been widely discussed in published literature, and there is also some development on the researches of turbulent film boiling. For example, Sarma et al. [6] presented turbulent film boiling under uniform heat flux condition on a horizontal cylinder. In the research, the assumption of equal shear condition both at the wall and the vapor-liquid interface is reasonable. About the turbulent film boiling on a horizontal isothermal circular cylinder, Sarma et al. [7] presented some theoretical results. The analysis compared the theoretical results with previous experimental results, and found that their results were in a good agreement with the experimental data. In addition, $\mathrm{Hu}[8]$ investigated the free convection in turbulent film boiling under the quiescent liquid on a sphere with variable wall temperature.

Even though there were many researches about laminar film boiling and turbulent film boiling on horizontal tubes, there was little publication about the turbulent film boiling with high velocity liquid. Predicting interfacial shear in a turbulent film boiling system under high velocity liquid is not easy. However, the present paper successfully predicts the vapor-liquid interfacial shear by using Colburn analogy. The present study applies the interfacial shear into the forced balance equation, and then combines the forced balance equation with the energy equation and thermal energy balance equation. At last, both the film thickness and Nusselt number are obtained. Besides, the present analysis also includes eddy diffusivity, radiation effects and temperature ratio. Finally, a comparison between the results of the present study and those reported in previous theoretical and experimental studies is provided. It is found that a good agreement exists between the two sets of results.

\section{Formulations}

Consider a horizontal tube immersed in flowing liquid with the high velocity $u_{\infty}$ and saturated temperature $T_{s}$. The wall temperature $T_{w}$ is assumed high enough to occur turbulent film boiling on the surface of the tube, and then a continuous film of vapor runs upward over the tube. The physical model and the coordinate system adopted in the present study are shown in Figure 1.

Boiling under the forced convection, the viscosity component and the buoyancy effect are assumed more significant than the inertia force. Then the force balance equation for the vapor film can be expressed as:

$$
\tau_{w}-\tau_{\delta}=g \delta\left(\rho_{l}-\rho_{s}\right) \sin \theta
$$

It is assumed the thickness of vapor film is much thinner than the radius of the tube $(\delta \ll R)$. And it's further assumed the turbulent conduction term across the vapor layer is more significant than the convective term, and hence the convective term can be neglected. The energy equation can be expressed as:

$$
\frac{\partial}{\partial y}\left\{\left(1+\frac{\varepsilon_{m}}{v} \operatorname{Pr}\right) \frac{\partial T}{\partial y}\right\}=0
$$

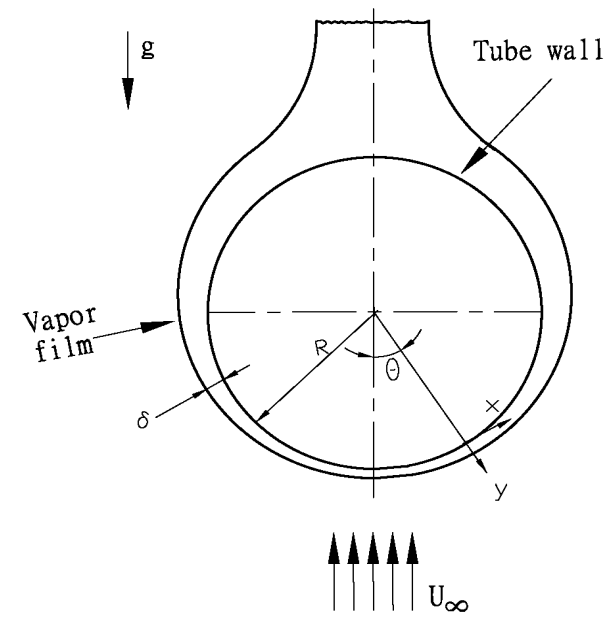

Figure 1. Physical model and coordinate system. 
The boundary conditions of energy equation under isothermal condition are as follows:

$T=T_{w}$ at $y=0$

$$
T=T_{s} \text { at } y=\delta \text { for } 0 \leq \theta \leq \pi
$$

For a pure substance, the thermal energy balance equation of the vapor film can be expressed as:

$$
\frac{\mathrm{d}}{\mathrm{d} \theta} \int_{0}^{\delta} \rho_{v} u \mathrm{~d} y=-\left.\frac{k_{w}}{h_{f g}} R \frac{\mathrm{d} T}{\mathrm{~d} y}\right|_{y=0}+\frac{\varepsilon \sigma R\left(T_{w}^{4}-T_{s}^{4}\right)}{h_{f g}}
$$

Under the high velocity liquid, the equation, which describes heat transfer in the flow around the tube, can be expressed as following equation:

$$
N u_{l}=C R e_{l}^{n-1} \operatorname{Pr}^{1 / 3}
$$

where $C$ is a constant in flow configuration. The constant value $C$ is listed in Table 1 .

According to Colburn analogy, the friction factor can be expressed as the following equation:

$$
\frac{f}{2}=S t \operatorname{Pr}^{2 / 3}
$$

The mean friction coefficient in the stream wise direction may then be written as:

$$
f=\frac{1}{\pi} \int_{0}^{\pi} f_{\theta} \mathrm{d} \theta
$$

Furthermore, the local friction can be obtained as:

$$
f_{\theta}=C \pi R e_{l}^{n-1} \sin \theta
$$

The turbulent boundary layer exerts a friction force on the liquid-vapor boundary. The shear stress is estimated by considering the external flowing liquid across the surface of the tube when there is no vapor film on the surface. The local friction coefficient is defined as:

$$
f_{\theta}=\tau_{\delta} /\left(\frac{1}{2} \rho_{l} u_{l}^{2}\right)
$$

According to potential flow theory, when the uniform liquid flow of velocity $u_{\infty}$ passing a tube, the liquid velocity at the edge of the boundary is as follows:

$$
u_{e}=2 u_{\infty} \sin \theta
$$

Combining Equation (8-10), the local shear stress can be expressed as:

$$
\tau_{\delta}=2 \pi C \rho_{l} u_{\infty}^{2} R e_{l}^{n-1} \sin ^{3} \theta
$$

Incorporating the interfacial vapor shear stress $\tau_{\delta}$ given by Equation (11) into the elemental forced balance equation enables Equation (1) to be rewritten in the following form:

$$
\tau_{w}=2 c \pi \rho_{l} u_{\infty}^{2} R e_{l}^{n-1} \sin ^{3} \theta+g \delta\left(\rho_{l}-\rho_{s}\right) \sin \theta
$$

Table 1. Values of $\mathrm{C}$ and $\mathrm{n}$ in Equation (5) ( ${ }^{*}$ data are used in the present paper).

\begin{tabular}{ccc}
\hline $\operatorname{Re}_{1}$ & $\mathrm{C}$ & $\mathrm{n}$ \\
\hline $0.4-4$ & 0.989 & 0.33 \\
$4-40$ & 0.911 & 0.385 \\
$40-4000$ & 0.683 & 0.466 \\
$4000-40,000$ & 0.193 & 0.618 \\
$40,000-400,000$ & $0.0266^{*}$ & $0.805^{*}$ \\
\hline
\end{tabular}


The forced balance equation Equation (12) yields the following dimensionless equation:

$$
R^{* 3}=R^{*} \varphi F^{\frac{n+1}{2}} \sin ^{3} \theta+\delta^{+} \sin \theta
$$

It's further assuming the pressure across the boundary layer is constant and the density variation across the boundary layer is given by the following equation:

$$
\rho T=\rho_{w} T_{w}=\rho_{s} T_{s}
$$

The energy equation Equation (2) yields the following dimensionless energy equation:

$$
\frac{\mathrm{d}}{\mathrm{d} y^{+}}\left[\left(1+\frac{\varepsilon_{m}}{v_{s}} \frac{P r}{\mu^{+}\left(T^{+}\right)\left(1+T^{+}\left(T_{r}-1\right)\right)}\right) \frac{\mathrm{d} T^{+}}{\mathrm{d} y^{+}}\right]=0
$$

The dimensionless boundary conditions of Equation (15) are:

$$
\begin{aligned}
& \text { (1) at } y^{+}=0 ; T^{+}=1 \\
& \text { (2) at } y^{+}=\delta^{+} ; T^{+}=0
\end{aligned}
$$

where the absolute viscosity equation $\mu^{+}$in dimensionless energy equation Equation (15) is expressed as the nitrogen at the saturation temperature corresponding to a system pressure under $1 \mathrm{~atm}$. i. e.

$$
\mu^{+}=\frac{\mu}{\mu_{s}}=2.656-3.804\left(\frac{T}{T_{s}}\right)+2.148\left(\frac{T}{T_{s}}\right)^{2}
$$

Besides, the thermal energy balance equation Equation (4) can be rewritten in dimensionless form as follows:

$$
\frac{\mathrm{d}}{\mathrm{d} \theta} \int_{0}^{\delta^{+}} \frac{u^{+}}{1+T^{+}\left(T_{r}-1\right)} \mathrm{d} y^{+}=T r S\left\{\left.(T r-1)\left(\frac{G r}{2}\right)^{\frac{1}{3}}\left(R^{* 3}-R \varphi F r^{\frac{n+1}{2}} \sin ^{3} \theta\right)^{1 / 3} k_{w}^{+} \frac{\mathrm{d} T^{+}}{\mathrm{d} y^{+}}\right|_{y^{+}=0}+N R\left(T_{r}^{4}-1\right)\right\}
$$

where the absolute conductivity equation $k^{+}$in thermal energy balance equation Equation (18) is expressed as the nitrogen the saturation temperature corresponding to a system pressure under $1 \mathrm{~atm}$. :

$$
k^{+}=\frac{k}{k_{s}}=236.1-811.5\left(\frac{T}{T_{s}}\right)+1045.4\left(\frac{T}{T_{s}}\right)^{2}-596.2\left(\frac{T}{T_{s}}\right)^{3}+127.2\left(\frac{T}{T_{s}}\right)^{4}
$$

Furthermore, the dimensionless thermal energy balance equation Equation (18) requires the velocity profile $u^{+}$in the vapor film. And $u^{+}$can be obtained by following equation [8]:

$$
\frac{\mathrm{d} u^{+}}{\mathrm{d} y^{+}}=\frac{1-2 \frac{y^{+}}{\delta^{+}}}{\frac{T}{T_{s}} \mu^{+}\left(T^{+}\right)\left[1+\frac{\varepsilon_{m}}{v_{s}} \frac{1}{\mu^{+}\left(T^{+}\right)\left(1+T^{+}\left(T_{r}-1\right)\right)}\right]}
$$

The boundary condition is:

$$
u^{+}=0, y^{+} / \delta^{+}=0 \text { at } y^{+}=0
$$

The eddy diffusivity distribution presented by Kato et al. [9] is expressed as:

$$
\frac{\varepsilon_{m}}{v_{s}}=0.4 y^{+}\left[1-\exp \left(-0.0017 y^{+2}\right)\right]
$$

The heat transfer of turbulent film boiling can be given by the following equation:

$$
h\left(T_{w}-T_{s}\right)=-\left.k_{w} \frac{\mathrm{d} T}{\mathrm{~d} y}\right|_{y=0}+\sigma \varepsilon\left[T_{w}^{4}-T_{s}^{4}\right]
$$


Obviously, the local Nusselt number can be expressed as:

$$
N u=-\left.k_{w}^{+} \frac{R^{*}}{G r^{1 / 3}} \frac{\mathrm{d} T^{+}}{\mathrm{d} y^{+}}\right|_{y^{+}=0}+2 N R\left(\frac{T_{r}^{4}-1}{T_{r}-1}\right)
$$

The mean Nusselt number for the entire surface of the tube can be written as:

$$
N u_{m}=\frac{1}{\pi} \int_{0}^{\pi}\left[-\left.k_{w}^{+} \frac{R^{*}}{G r^{1 / 3}} \frac{\mathrm{d} T^{+}}{\mathrm{d} y^{+}}\right|_{y^{+}=0}+2 N R\left(\frac{T_{r}^{4}-1}{T_{r}-1}\right)\right] \mathrm{d} \theta
$$

\section{Numerical Method}

The dimensionless governing Equations (13), (15)-(22) and (24)-(25) subject to the relevant boundary conditions given can be used to estimate $\delta^{+}, R^{*}$ and $\mathrm{Nu}$ for the vapor film by means of the following procedures by using $C^{++}$:

1) Suitable dimensionless parameters, such as $T_{r}, S, N R, F r$ and $G r$ are specified.

2) The boundary conditions of velocity and temperature are as follows:

$$
\begin{aligned}
& \text { at } y^{+}=0 ; T^{+}=1, u^{+}=0, \mu^{+}=2.656-3.804 T_{r}+2.148 T_{r}^{2} \\
& k^{+}=236.1-811.5 T_{r}+1045.4 T_{r}^{2}-596.2 T_{r}^{3}+127.2 T_{r}^{4} \\
& \text { at } y^{+}=\delta^{+} ; T^{+}=0
\end{aligned}
$$

3) At the bottom of the tube, $\theta=0, i=0$, the dimensionless film thickness $\delta^{+}$is also zero

$\left(\delta^{+}=\frac{\delta u^{*}}{v}=\frac{\delta 0}{v}=0\right)$. At the next node, i.e. $i=i+1$, the value of $\theta$ is given by $\theta_{i+1}=\theta_{i}+\Delta \theta$, where $\Delta \theta=(\pi / 720)$.

4) Guess an initial value of $\delta^{+}$; substitute Equations (17), (22) into Equations (15) and (16) and then get the value of $\left.\frac{\mathrm{d} T^{+}}{\mathrm{d} y^{+}}\right|_{y^{+}=0}$.

5) Substitute $\left.\frac{\mathrm{d} T^{+}}{\mathrm{d} y^{+}}\right|_{y^{+}=0}$, Equations (19), (20) and (22) into Equation (18), and get the value of $R^{* 3}-R^{*} \varphi F^{\frac{n+1}{2}} \sin ^{3} \theta$. After calculating, the values of $R^{*}$ can be gotten, and then substitute the values of $R^{*}$ into Equation (13).

6) The criterion for the accuracy of $\delta^{+}$is assessed by Equation (13), and the equation can be rewritten in the following form: $\delta^{+} \sin \theta=R^{* 3}-R^{*} \varphi F r^{\frac{n+1}{2}} \sin ^{3} \theta$. The equation can be written more clearly as the following form:

$$
\delta^{+}-\frac{R^{* 3}-R^{*} \varphi F r^{\frac{n+1}{2}} \sin ^{3} \theta}{\sin \theta}=0
$$

Furthermore, the error of the numerical calculation is less than $10^{-6}$, and the precision is good enough. It can be expressed as the following unequal equation:

$$
\delta^{+}-\frac{R^{* 3}-R^{*} \varphi F r^{\frac{n+1}{2}} \sin ^{3} \theta}{\sin \theta} \leq 10^{-6}
$$

If the calculation is a convergence, process the film thickness of next angular position. If the calculation is not a convergence, guess a new thickness and repeat processes (4)-(6).

7) The process above is repeated at the next node position, i.e. $\theta_{i+1}=\theta_{i}+\Delta \theta$, and then subsequently at all 
nodes within the range $0 \leq \theta \leq \pi$.

8) The local Nusselt number and mean Nusselt number are then calculated.

9) The flow chart for calculating the vapor thickness is expressed in Figure 2.

\section{Results and Discussion}

Figure 3 presents dimensionless local vapor velocity. The dimensionless velocity of the tube wall is zero under the no-slip condition. Then, the velocity increases along the $y$-direction, and because of the shear stress of vapor-liquid interfacial, it becomes larger and larger. Besides, the velocity will increase along with the increase of the angle. And the velocity will reach the maximum value at the top of the tube.

Figure 4 presents the dimensionless temperature distribution for entire angular positions along with the vapor film thickness direction $y^{+}$. Because assuming the stagnation point is at the bottom of the tube, the figure shows a linear temperature distribution at the bottom of the tube. Besides, the present paper considers the interfacial

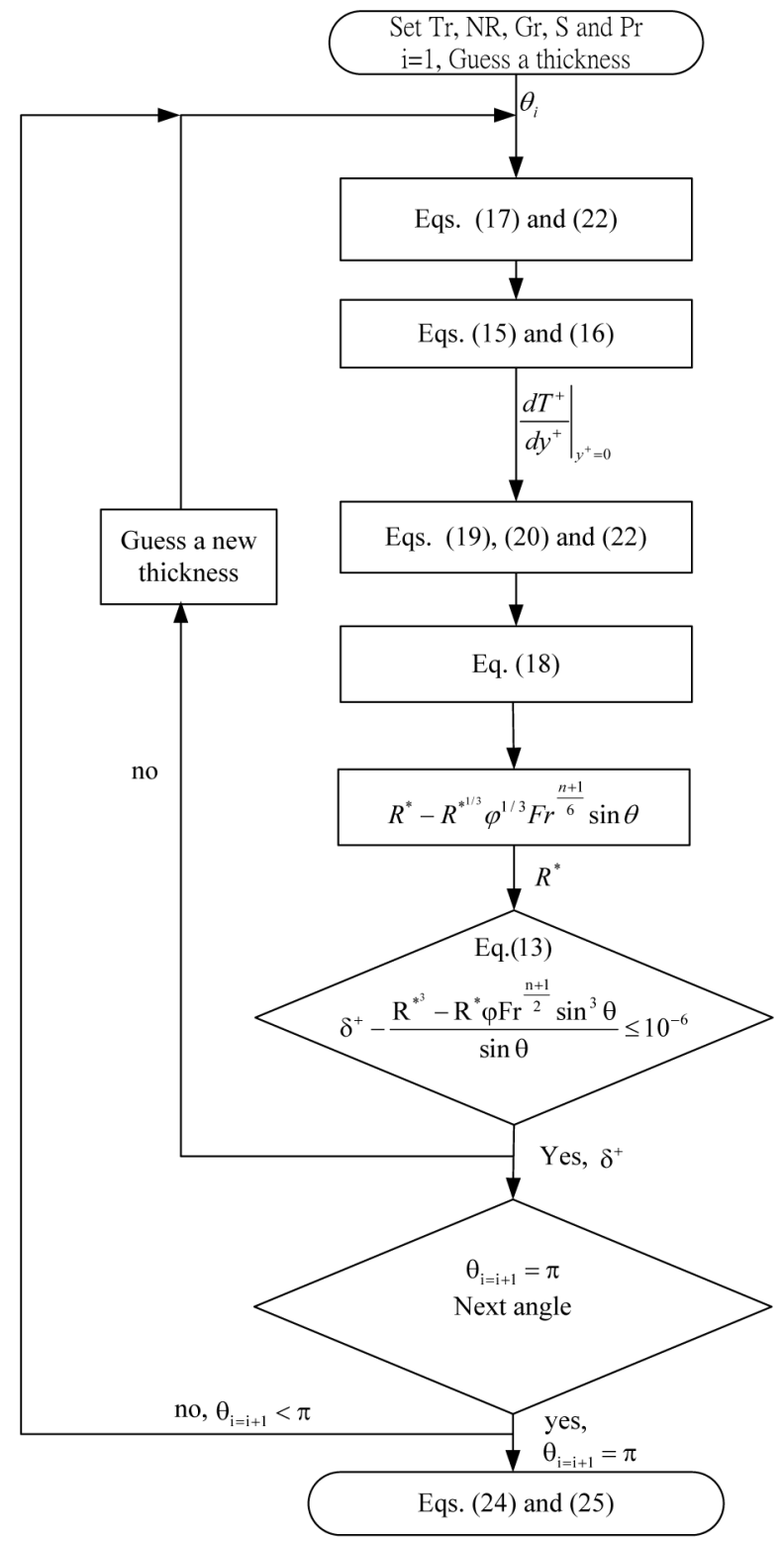

Figure 2. The flow chart for calculating the vapor thickness and Nusselt number. 


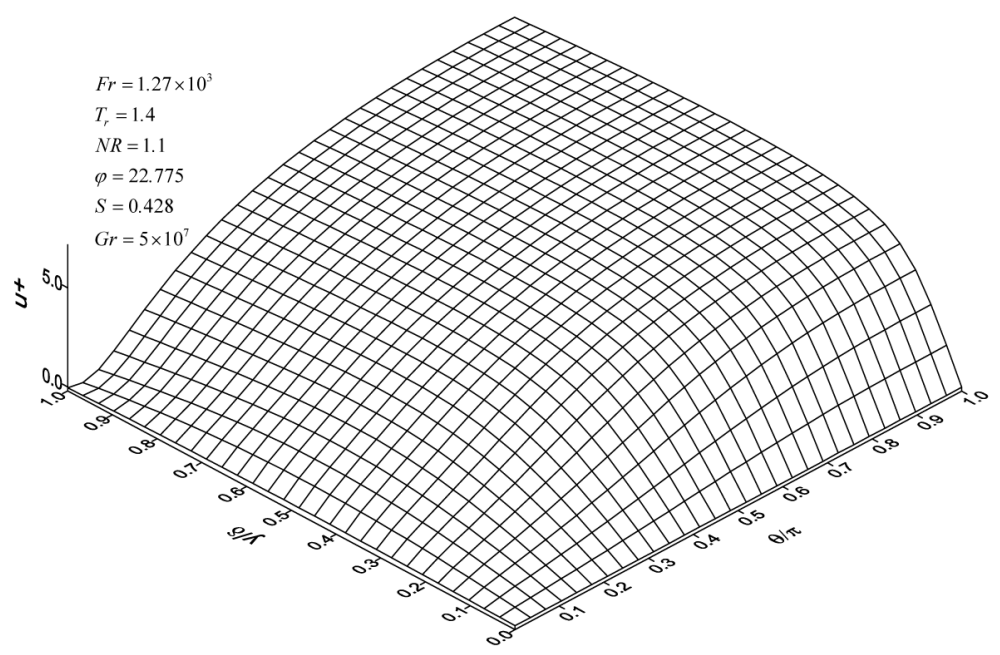

Figure 3. Local velocity distribution in vapor film.

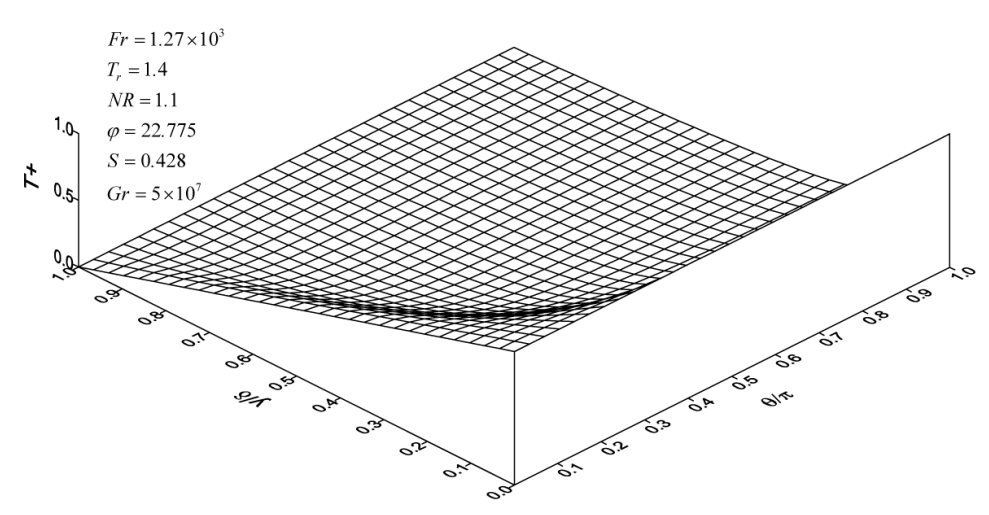

Figure 4. Local temperature distribution in vapor film.

shear with high velocity liquid under the effects of turbulence; thus, when the angular position increases, the non-linear temperature distribution of the profile is becoming more and more significant.

Figure 5 presents the variation of the dimensionless vapor thickness of the tube. Specifically, the film thickness increases continuously from a minimum value at the bottom of the tube $\left(\theta=0^{\circ}\right)$ as the value of $\theta$ increases. It can be seen that the film thickness reaches its maximum value at the top of the tube $\left(\theta=180^{\circ}\right)$. Furthermore, the increase of the Froude number, $F r$ will bring out the increase of the interfacial shear and lead to the increase of the evaporative rate. And the increase of the evaporative rate also leads to an increase of the vapor film thickness.

Figure 6 presents the relationship between the mean Nusselt number and the Froude numbers for five values of Grashof number. The figure shows the results of the forced convection film boiling. A higher Froude number will bring an increase in the mean Nusselt. Besides, the Grashof number $\mathrm{Gr}$ is also one of the dominant factors, and therefore increasing the Grashof number will bring out an increase in the mean Nusselt.

Figure 7 provides a comparison between the present results for the mean Nusselt number and the results generated in a previous study [10]. The range of $R a$ in Pomerantz's research was $3.5 \times 10^{7} \leq R a \leq 3 \times 10^{8} . R a$ in the present research is defined as modified Rayleigh number, $R a=\operatorname{Gr} \operatorname{Pr}\left[0.5+1 / S\left(T_{r}-1\right)\right]$. And the range of Ra of the present study is $10^{7} \leq R a \leq 10^{11}$. The figure shows that the mean Nusselt number calculated in the present study is broadly similar to the results generated by Sarma et al. [8] for the range of $R a$ of $10^{7} \leq R a \leq 10^{11}$. When $F r=0, u_{\infty}=0$, there is a good agreement between Sarma et al.'s results which is under the condition of quiescent liquid and the present data.

Besides, the figure also compares the present results with the experimental results [9] obtained in an earlier study for laminar film boiling. It can be seen that there is a similar trend between the two sets of results at both 


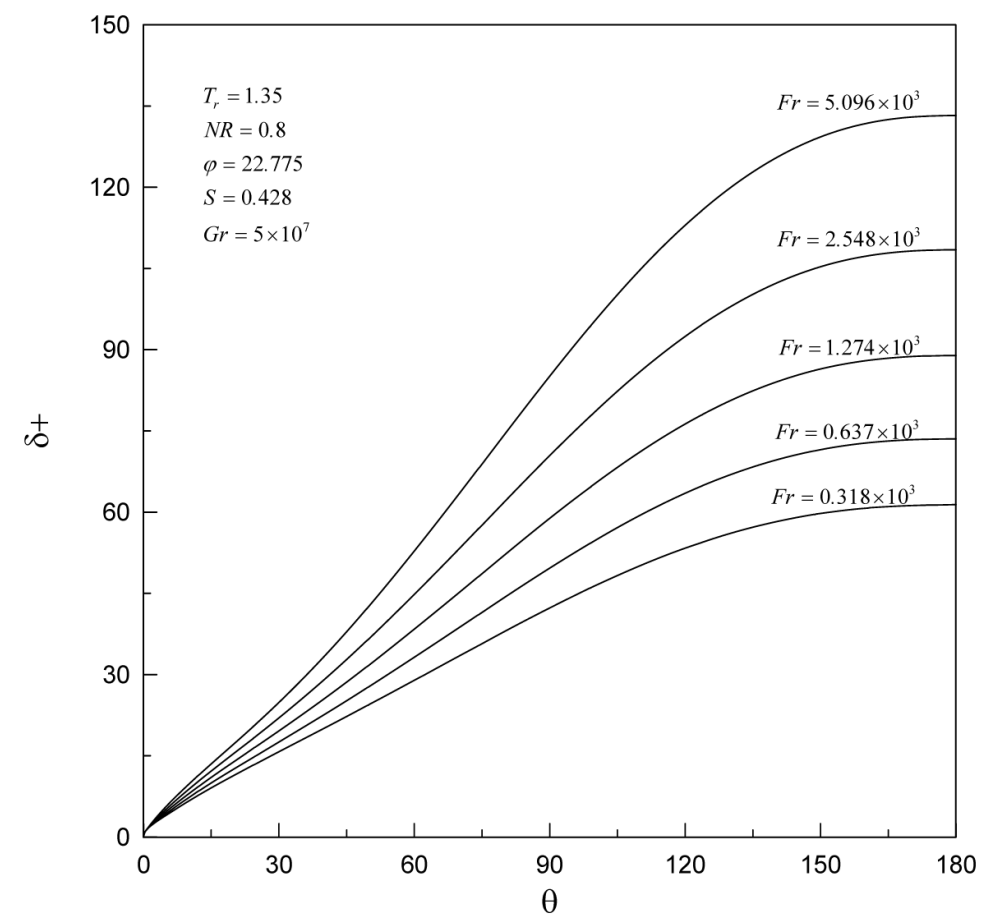

Figure 5. Dimensionless film thickness on tube surface.

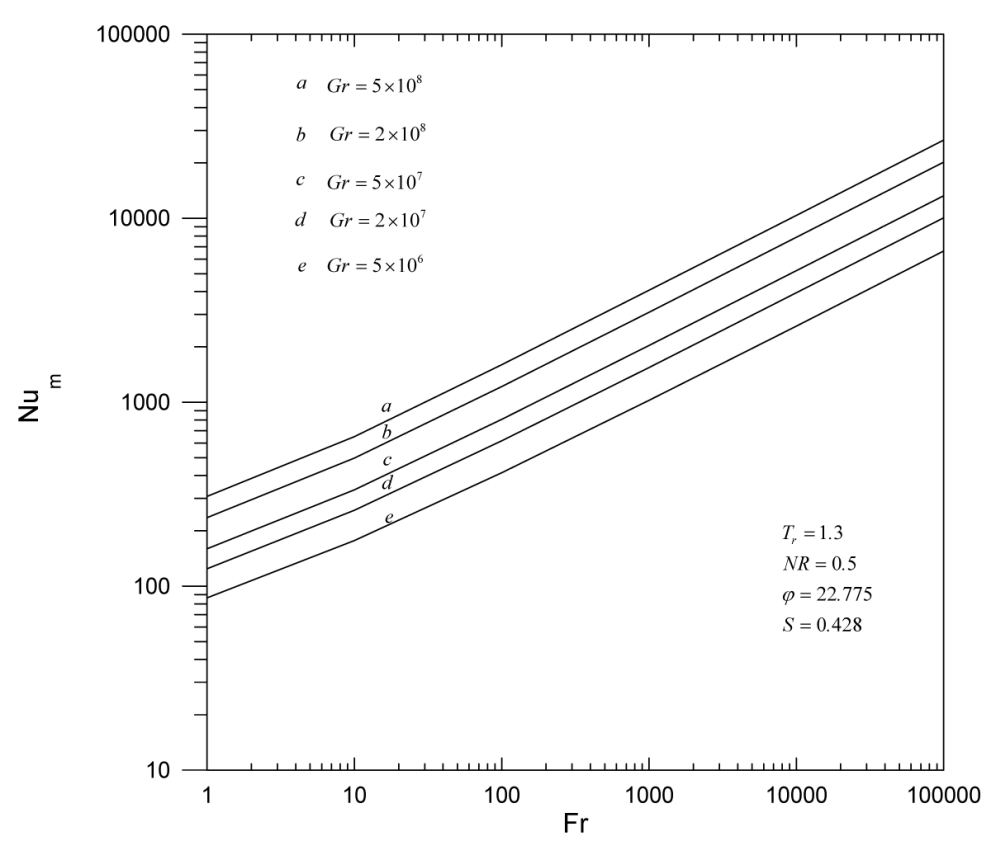

Figure 6. Effects of the $F r$ on mean Nusselt number.

low and mid $R a$ number. Besides, the increase of the $R a$ values leads to an increase of the mean Nusselt number. The increase in the Froude number will also bring out an increase in the mean Nusselt number.

\section{Conclusions}

The following conclusions can be drawn from the results of the present theoretical study: 


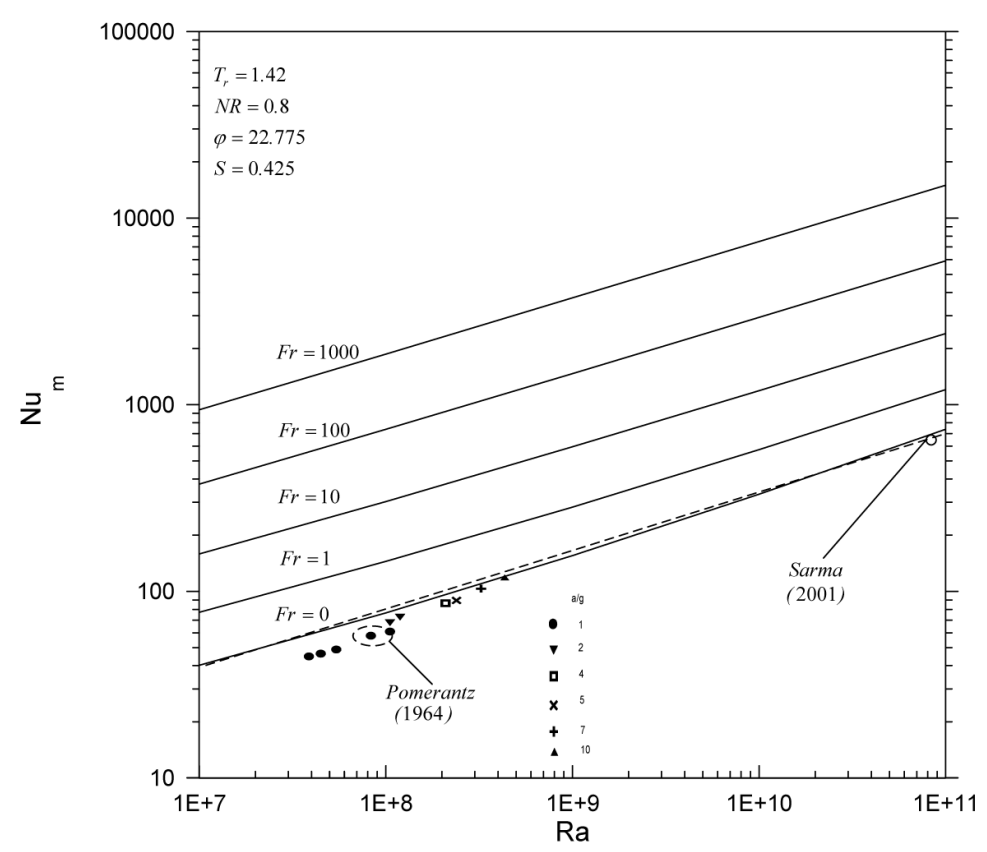

Figure 7. Effects of the Ra on mean Nusselt number.

1) With the help of Colburn analogy, the present research successfully predicts the shear stress of the vaporliquid interface in a film boiling system under high velocity of liquid.

2) The increase in the Grash of number will lead to an increase in the mean Nusselt number. Besides, turbulent film boiling under the high velocity of external flowing liquid, the increase in the Froude number will bring out an increase in the mean Nusselt number.

3) It shows a good agreement between the present result which is under the condition of $F r=0$ and the previous studies with free convection.

\section{Acknowledgements}

The authors gratefully acknowledge the support provided to this projects by the Ministry of Science and Technology of Taiwan under Contract Number MOST 104-2221-E-019-052.

\section{References}

[1] Bromley, L.A. (1950) Heat Transfer in Stable Film Boiling. Chemical Engineering Progress, 46, 221-227.

[2] Nishikawa, K. and Ito, T. (1966) Two-Phase Boundary-Layer Treatment of Free Convection Film Boiling. International Journal of Heat and Mass Transfer, 9, 109-115. http://dx.doi.org/ 10.1016/0017-9310(66)90125-6

[3] Jordan, D.P. (1968) Film and Transition Boiling. Advances in Heat Transfer, 5, 55-128. http://dx.doi.org/10.1016/S0065-2717(08)70129-1

[4] Sakurai, A., Shiotsu, M. and Hata, K.A. (1990) General Correlation for Pool Film Boiling Heat Transfer from a Horizontal Cylinder to Subcooled Liquid: Part 1-A Theoretical Pool Film Boiling Heat Transfer Models Including Radiation Contributions and Its Analytical Solution. Journal of Heat Transfer, 112, 430-440. http://dx.doi.org/10.1115/1.2910396

[5] Huang, L. and Witte, L.C. (1995) Forced Convection Film Boiling Heat Transfer Around Horizontal Cylinders in Highly Subcooled. ASME/JSME Thermal Engineering Conference, 2, 315-322.

[6] Sarma, P.K., Rao, V.D. and Bergles, A.E. (1997) Turbulent Film Boiling on a Horizontal Cylinder-Effect of Temperature Dependent. Energy Conversion and Management, 38, 1135-1144. http://dx.doi.org/10.1016/S0196-8904(96)00143-4

[7] Sarma, P.K., Subrahmanyam, T., Rao, V.D. and Bergles, A.E. (2001) Turbulent Film Boiling on a Horizontal Cylinder. International Journal of Heat and Mass Transfer, 44, 207-214. http://dx.doi.org/10.1016/S0017-9310(00)00061-2 
[8] Hu, H.P. (2008) An Analysis of Turbulent Film Boiling on a Sphere with Variable Wall Temperature. IMechE, Part C: Journal of Mechanical Engineering Science, 222, 1515-1521. http://dx.doi.org/10.1243/09544062JMES943

[9] Kato, H., Shiwaki, N.N. and Hirota, M. (1968) On the Turbulent Heat Transfer by Free Convection From a Vertical Plate. International Journal of Heat and Mass Transfer, 11, 1117-1125. http://dx.doi.org/10.1016/0017-9310(68)90029-X

[10] Pomerantz, M.L. (1964) Film Boiling on a Horizontal Tube in Increased Gravity Fields. Journal of Heat Transfer, 86, 213-219. http://dx.doi.org/10.1115/1.3687099

\section{Nomenclature}

$a$ acceleration due to graviton force $\left(\mathrm{m} / \mathrm{sec}^{2}\right)$

$C_{p}$ specific heat capacity $(\mathrm{J} / \mathrm{kg} \cdot \mathrm{K})$

$D$ diameter of tube, $2 R$

$R^{+}$shear Reynolds, $R u^{*} / v_{s}$

$R^{*}$ wall shear parameter, $R^{+} / G r^{1 / 3}$

Fr Froude number, $\frac{u_{\infty}^{2}}{g R}$

$G r$ modified Grashof number, $\frac{g D^{3}}{v_{s}^{2}} \frac{\rho_{l}-\rho_{s}}{\rho_{s}}$

$g$ acceleration due to gravity $\left(\mathrm{m} / \mathrm{sec}^{2}\right)$

$h$ heat transfer coefficient, $\mathrm{w} /\left(\mathrm{m}^{2} \mathrm{k}\right)$

$h_{f g}$ latent heat $(\mathrm{J} / \mathrm{kg})$

$k$ thermal conductivity $(\mathrm{W} / \mathrm{m} \cdot \mathrm{k})$

$k^{+}$dimensionless thermal conductivity, $k(T) / k\left(T_{s}\right)$

$\left.k_{w}^{+} \quad k(T)\right|_{y^{+}=0} / k\left(T_{s}\right)$

$\mathrm{Nu}$ Local Nusselt number, $h R / k_{s}$

$N u_{m}$ mean Nusselt number

$N R$ radiation parameter, $\varepsilon \sigma T_{s}^{3} R / k_{s}$

$\operatorname{Pr}$ Prandtl number, $C_{p} \mu / k$

$R$ Radius of tube (m)

$R a$ modified Rayleigh number, $G r \operatorname{Pr}\left[0.5+1 / S\left(T_{r}-1\right)\right]$

$R e_{v}$ Reynolds number of vapor, $\frac{u_{\infty} D}{v_{v}}$

$S$ heat capacity parameter, $C_{p} T_{s} /\left(h_{f g} P r\right)$

St Stanton number, $\mathrm{Nu} /(\mathrm{RePr})$

$T$ temperature $(\mathrm{K})$

$T_{r}$ temperature ratio, $T_{w} / T_{s}$

$T^{+}$dimensionless temperature, $\left(T-T_{s}\right) /\left(T_{w}-T_{s}\right)$

$u$ vapor velocity in $x$-direction $(\mathrm{m} / \mathrm{s})$

$u^{*}$ shear velocity, $\sqrt{\tau_{w} / \rho_{s}}$ 
$u^{+}$dimensionless velocity, $u / u^{*}$

$v$ velocity normal to the direction of flow $(\mathrm{m} / \mathrm{s})$

$x$ peripheral coordinate $(\mathrm{m})$

$y$ coordinate measured distance normal to tube surface (m)

$y^{+}$dimensionless distance, $y u^{*} / v_{s}$

\section{Greek Symbols}

$\delta$ vapor film thickness (m)

$\delta^{+}$dimensionless film thickness, $\delta u^{*} / v_{s}$

$\mu$ absolute viscosity $(\mathrm{kg} / \mathrm{m} \cdot \mathrm{s})$

$\mu^{+}$dimensionless absolute viscosity, $\mu / \mu_{s}$

$v$ kinematic viscosity $\left(\mathrm{m}^{2} / \mathrm{s}\right)$

$\rho$ density $\left(\mathrm{kg} / \mathrm{m}^{3}\right)$

$\tau$ shear stress $\left(\mathrm{N} / \mathrm{m}^{2}\right)$

$\theta$ angle measured from bottom of tube

$\varphi$ interfacial shear parameter, $2^{n} \pi C\left(\frac{v_{s}}{v_{l}}\right)^{n-1}\left(\frac{\rho_{l}-\rho_{s}}{\rho_{s}}\right)^{\frac{1-n}{2}} G r^{\frac{3 n-1}{6}}$

$\varepsilon_{m}$ eddy diffusivity for momentum

$\varepsilon$ emissivity

$\sigma$ Stefan-Boltzmann constant, $\mathrm{w} / \mathrm{m}^{2} \cdot \mathrm{k}^{4}$

\section{Subscripts}

$l$ liquid

$s$ vapor at saturation temperature

$v$ vapor

$w$ tube wall

$x$-direction

$\delta$ vapor-liquid interface 